
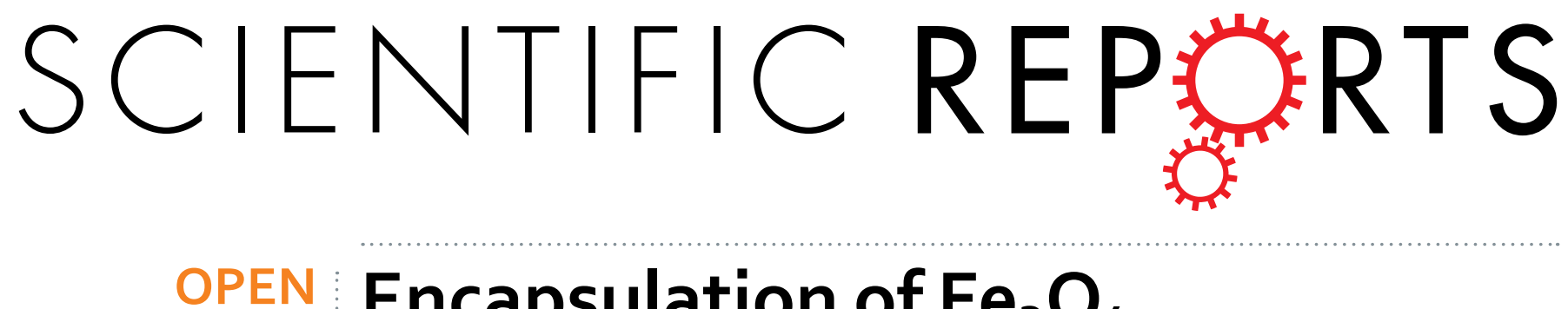

\title{
Encapsulation of $\mathrm{Fe}_{3} \mathrm{O}_{4}$
}

Nanoparticles into N, S co-Doped Graphene Sheets with Greatly

Received: 01 March 2016

Accepted: 27 May 2016

Published: 14 June 2016

\section{Enhanced Electrochemical Performance}

\author{
Zunxian Yang ${ }^{1}$, Kun Qian ${ }^{1}$, Jun Lv ${ }^{1}$, Wenhuan Yan ${ }^{1}$, Jiahui Liu ${ }^{1}$, Jingwei Ai $^{1}$, Yuxiang Zhang ${ }^{1}$, \\ Tailiang Guo ${ }^{1}$, Xiongtu Zhou ${ }^{1}$, Sheng Xu ${ }^{1}$ \& Zaiping Guo ${ }^{2,3}$
}

Particular $\mathrm{N}, \mathrm{S}$ co-doped graphene/ $\mathrm{Fe}_{3} \mathrm{O}_{4}$ hybrids have been successfully synthesized by the combination of a simple hydrothermal process and a subsequent carbonization heat treatment. The nanostructures exhibit a unique composite architecture, with uniformly dispersed $\mathrm{Fe}_{3} \mathrm{O}_{4}$ nanoparticles and N, S co-doped graphene encapsulant. The particular porous characteristics with many meso/micro holes/pores, the highly conductive N, S co-doped graphene, as well as the encapsulating N, S co-doped graphene with the high-level nitrogen and sulfur doping, lead to excellent electrochemical performance of the electrode. The $\mathrm{N}-\mathrm{S}-\mathrm{G} / \mathrm{Fe}_{3} \mathrm{O}_{4}$ composite electrode exhibits a high initial reversible capacity of $1362.2 \mathrm{mAhg}^{-1}$, a high reversible specific capacity of $1055.20 \mathrm{mAhg}^{-1}$ after 100 cycles, and excellent cycling stability and rate capability, with specific capacity of $556.69 \mathrm{mAhg}^{-1}$ when cycled at the current density of $1000 \mathrm{mAg}^{-1}$, indicating that the $\mathrm{N}-\mathrm{S}-\mathrm{G} / \mathrm{Fe}_{3} \mathrm{O}_{4}$ composite is a promising anode candidate for Li-ion batteries.

The emergence of electric vehicles (EV) and hybrid electric vehicles (HEV) and the popularity of portable electronics, as well as the applications of the power grid, trigger the requirement of rechargeable batteries with both high-energy capacity and power density. Of all the energy storage devices, lithium ion batteries (LIBs), have attracted more and more attention mainly due to their most possibilities in meeting the requirements for the high energy equipment including electric vehicles (EV), hybrid electric vehicles (HEV) and the power grid ${ }^{1-6}$. The suitable nanomaterials and nanostructures that allow fast charge-discharge rate capability would be one of the most important respects to the high-performance lithium ion batteries. Many electrode materials, especially anode materials, such as $\mathrm{Si}^{7}, \mathrm{SnO}_{2}{ }^{8,9}, \mathrm{CuO}^{10}$ and some other transition metal oxides, have been investigated and used for the lithium ion battery. Of all those anode materials mentioned-above, $\mathrm{Fe}_{3} \mathrm{O}_{4}$ has absorbed great interests to many researchers on the lithium ion battery, mainly due to its particular advantages ${ }^{1,11,12}$ of nature's abundance, environmental benignity, high electronic conductivity, low cost and much higher storage capacity $\left(\mathrm{Fe}_{3} \mathrm{O}_{4}: 926 \mathrm{~mA} \mathrm{~h} \mathrm{~g}^{-1}\right)$ as compared with the traditional carbonaceous anode materials (Graphite: $372 \mathrm{~mA} \mathrm{~h} \mathrm{~g}{ }^{-1}$ ). The practical application of $\mathrm{Fe}_{3} \mathrm{O}_{4}$ in lithium-ion batteries, however, is greatly hampered by its poor cycling performance, as well as its vulnerability to agglomeration and mechanical strain originating from the large volume variation during the lithiation/delithiation processes, which results in severe loss of capacity, increased diffusion lengths and decreased electrical conductivity ${ }^{13-16}$.

During the past decades, tremendous efforts have been made to overcome these problems mentioned above. One efficient strategy is to design the nanomaterials or nanostructures via reducing the particle size of $\mathrm{Fe}_{3} \mathrm{O}_{4}$ down to the nanometer scale, which could accommodate or buffer the volume changes, greatly reduce the strain

${ }^{1}$ National \& Local United Engineering Laboratory of Flat Panel Display Technology, Fuzhou University, Fuzhou 350002, P. R. China. 'Institute for Superconducting \& Electronic Materials, University of Wollongong, NSW 2522, Australia. ${ }^{3}$ School of Mechanical, Materials \& Mechatronics Engineering, University of Wollongong, NSW 2522, Australia. Correspondence and requests for materials should be addressed to Z.Y. (email: yangzunxian@ @hotmail.com) orT.G. (email: gtlfzu@hotmail.com) or Z.G. (email:zguo@uow.edu.au) 


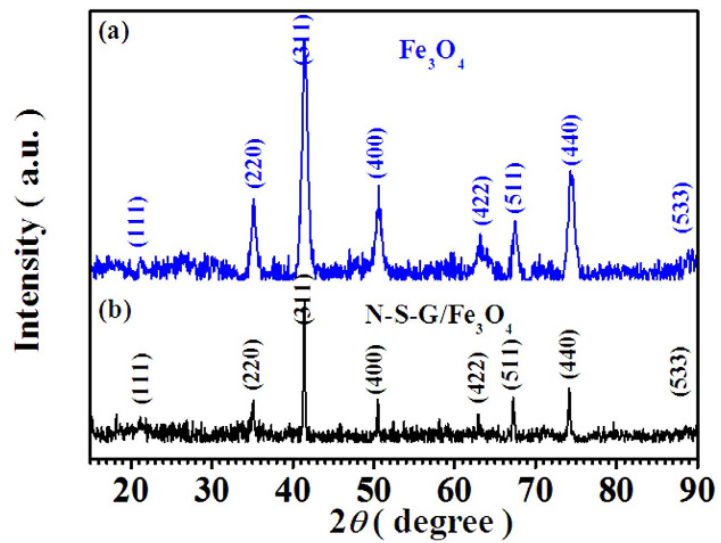

Figure 1. X-ray diffraction patterns of as-prepared $\mathrm{Fe}_{3} \mathrm{O}_{4}$ nanoparticles and $\mathrm{N}-\mathrm{S}-\mathrm{G} / \mathrm{Fe}_{3} \mathrm{O}_{4}$ composite, respectively. (a) $\mathrm{Fe}_{3} \mathrm{O}_{4}$ nanoparticles with cubic structure (JCPDS 19-0629), (b) N-S-G/ $\mathrm{Fe}_{3} \mathrm{O}_{4}$ composite with cubic structure (JCPDS 19-0629), as indexed in the patterns.

that originates from the lithiation and dilithiation process, directly shorten the transport path and the diffusion time for lithium ions, and furthermore, offer more active sites for lithium ions during charge/discharge cycling processes. Many nano-scale $\mathrm{Fe}_{3} \mathrm{O}_{4}$ architectures, such as nanotubes ${ }^{16-18}$, nanobelts ${ }^{19}$, nanofibers ${ }^{20,21}$, nanospheres ${ }^{22,23}$, nanorods $s^{24,25}$, and so on, have been prepared by many different methods, including the hydrothermal method ${ }^{26}$, the solvothermal route ${ }^{27}$, the electrospinning method ${ }^{21}$, electrochemical techniques, etc. Another alternative strategy is to combine $\mathrm{Fe}_{3} \mathrm{O}_{4}$ in the form of nanostructures with a high conductivity matrix including various metal nanostructures ${ }^{1,28}$, carbon materials ${ }^{27,29}$ and other stable materials, which could cushion the mechanical effects aroused during the charge/discharge process and simultaneously improve the conductivity of the composite. Up to now, hybridization of carbon materials including the amorphous carbon ${ }^{20}$, carbon nanotube ${ }^{16,30}$, and the recently-developed graphene with $\mathrm{Fe}_{3} \mathrm{O}_{4}$ may be one of the most effective solution. Especially, graphene, as one of carbon materials with honeycomb crystal lattice and one-atom thick planar characteristics, have provided great opportunities in enhancing the performance of $\mathrm{Fe}_{3} \mathrm{O}_{4}$ as the LIB electrodes ${ }^{31-33}$ owing to its excellent electrical conductivity, high mechanical flexibility, large specific surface area, and pronounced thermal and chemical stability. Recently, introducing heteroatoms such as N, B and S etc. into graphene can effectively enhance the lithium storage capacity of graphene-based composite ${ }^{34,35}$ mainly owing to greatly increased charged sites and conductivity in the heteroatom doped graphen $e^{36}$, which would greatly mitigate the negative effect of graphene content on the lithium ion storage capacity of composite. However, at present, the heteroatom doped graphene $/ \mathrm{Fe}_{3} \mathrm{O}_{4}$ composites are still a long way from being ideal anode candidates for LIBs mainly because there are many challenges in forming bi-heteroatom doped graphene/ $\mathrm{Fe}_{3} \mathrm{O}_{4}$ composites and enhancing the content of heteroatom doped in the composite.

In this paper, a simple and low-cost strategy is reported to build novel N, S co-doped graphene $/ \mathrm{Fe}_{3} \mathrm{O}_{4}$ architectures with $\mathrm{Fe}_{3} \mathrm{O}_{4}$ nanoparticles encapsulated into the $\mathrm{N}, \mathrm{S}$ co-doped graphene sheets by a hydrothermal process, followed by a subsequent carbonization treatment. Apart from combining the advantages of nanoscale $\mathrm{Fe}_{3} \mathrm{O}_{4}$ particles with those of $\mathrm{N}, \mathrm{S}$ co-doped graphene, the novel $\mathrm{N}, \mathrm{S}$ co-doped graphene $/ \mathrm{Fe}_{3} \mathrm{O}_{4}$ nanostructure has many unique advantages such as particular bi-heteroatom-doped graphene/ $\mathrm{Fe}_{3} \mathrm{O}_{4}$ nanoarchitecture, meso/micro porosities surrounded by many randomly-aligned $\mathrm{N}, \mathrm{S}$ co-doped graphene nanosheets, large surface-to-volume ratio, and excellent conductivity including both ionic conductivity and electronic conductivity mainly owing to the highly conductive $\mathrm{N}, \mathrm{S}$ co-doped graphene nanosheets, as well as the high heteroatom-content in the N, S co-doped graphene $/ \mathrm{Fe}_{3} \mathrm{O}_{4}$ nanostructures. The $\mathrm{N}, \mathrm{S}$ co-doped graphene $/ \mathrm{Fe}_{3} \mathrm{O}_{4}$ nanostructures have been investigated in a preliminary way for potential use as an anode material for the lithium ion battery and have exhibited excellent cycling stability and rate capability.

\section{Results}

The X-ray diffraction patterns of as-prepared $\mathrm{Fe}_{3} \mathrm{O}_{4}$ nanoparticles and N, S co-doped graphene $/ \mathrm{Fe}_{3} \mathrm{O}_{4}(\mathrm{~N}-\mathrm{S}$-G/ $\mathrm{Fe}_{3} \mathrm{O}_{4}$ ) composites, as shown in Fig. 1, reveal that the nanopowders synthesized by simple LPR process via just controlling the mole ratio of $\mathrm{Fe}^{3+}$ to $\mathrm{Fe}^{2+}$ in the precursor solution belong to typical $\mathrm{Fe}_{3} \mathrm{O}_{4}$ with cubic spinel structure (JCPDS 19-0629) $)^{1,29,37}$ according to the obvious reflections from their characteristic lattice planes (220), (311), (400), (422), (511) and (440) (see Fig. 1(a)). When dicyandiamide and thiourea, as well as iron chloride, were dispersed into the GO suspension in turn and experienced hydrothermal process, as illustrated in Fig. 2(a,b), the iron chloride was hydrolyzed to form $\mathrm{FeOOH}$ particles ${ }^{38,39}$ embedded and grown on graphene surface, and simultaneously, Nitrogen and Sulfur species were incorporated into the graphene lattices during the hydrothermal reaction between dicyandiamide or thiourea and hydroxyl $(-\mathrm{OH})$ or carboxyl $(-\mathrm{COOH})$ in graphene sheets, respectively. Subsequently, after dehydration reaction in $500^{\circ} \mathrm{C}$ nitrogen environment, the $\mathrm{FeOOH}$ particles were finally transferred to $\mathrm{Fe}_{3} \mathrm{O}_{4}$ nanoparticles encapsulated into N, S co-doped graphene nanosheets (see Fig. 2(c)). As shown in Fig. 1(b), thenanostructuresN-S-G/Fe $\mathrm{O}_{4}$ nanostructures is also ascribed to typical $\mathrm{Fe}_{3} \mathrm{O}_{4}$ phase with cubic spinel structure (JCPDS 19-0629), which is in good accordance with that of the pure $\mathrm{Fe}_{3} \mathrm{O}_{4}$ sample, and no other diffraction peaks of graphene and N, S co-doped graphene can be found (see Fig. 1(b)). Raman 


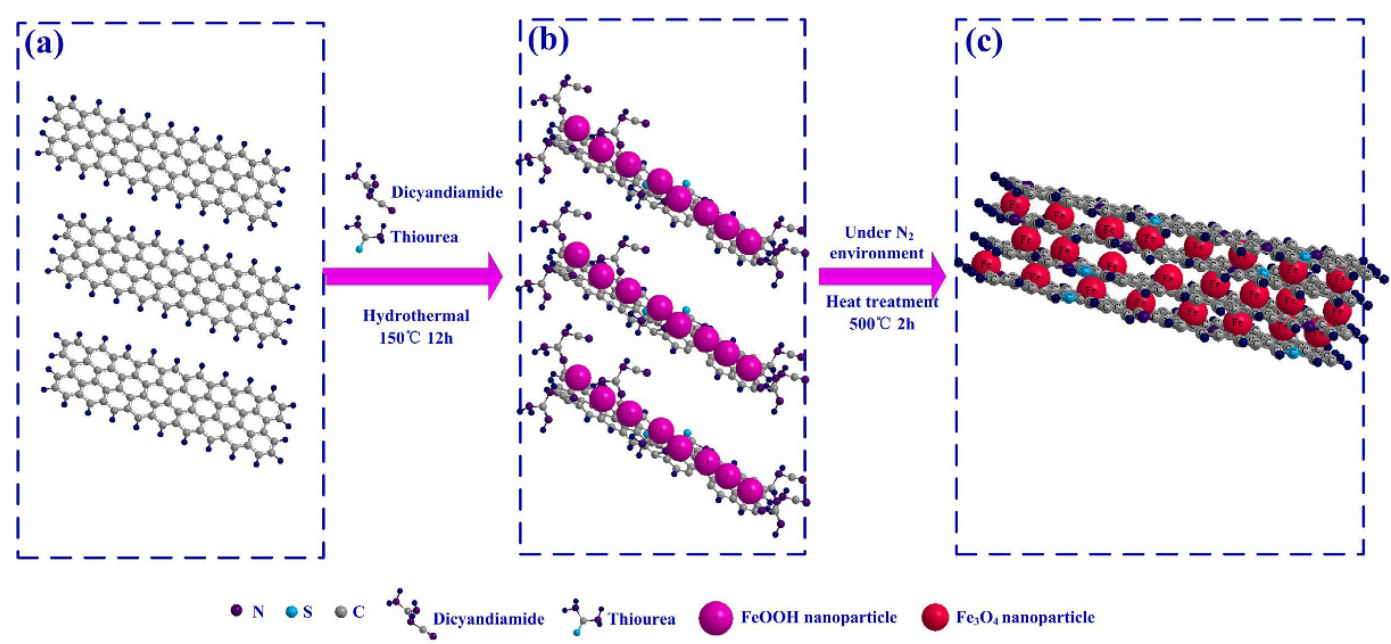

Figure 2. The growth mechanism of Nitrogen and Sulfur co-doped graphene $/ \mathrm{Fe}_{3} \mathrm{O}_{4}$ composite: (a) graphene sheets, (b) formation of N,S co-decorated graphene/FeOOH nanoparticles composite after hydrothermal reaction, (c) formation of $\mathrm{N}, \mathrm{S}$ co-doped graphene/ $\mathrm{Fe}_{3} \mathrm{O}_{4}$ composite after heat treatment in $\mathrm{N}_{2}$ atmosphere.

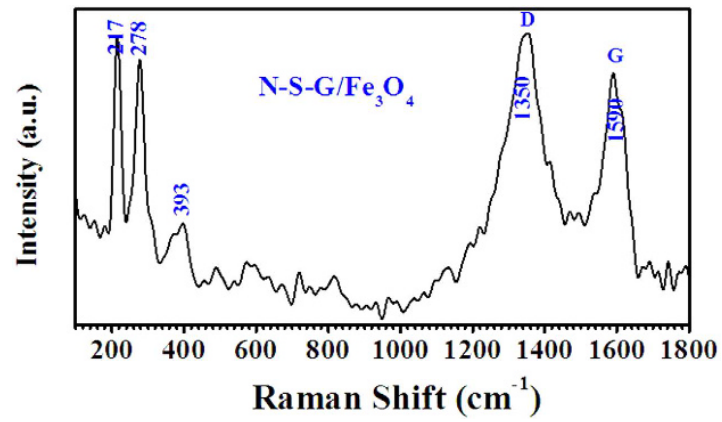

Figure 3. Raman spectra for the as-synthesized N-S-G/Fe $\mathrm{O}_{3}$ composite.

spectroscopic analysis was further employed to explore the composition of the N-S-G/Fe $\mathrm{O}_{4}$ nanostructures. As depicted in Fig. 3, the scattering peaks at $217,278,393 \mathrm{~cm}^{-1}$ are mainly attributable to the $\mathrm{E}_{\mathrm{g}}, \mathrm{T}_{2 \mathrm{~g}}$, and $\mathrm{A}_{1 \mathrm{~g}}$ vibration modes of $\alpha-\mathrm{Fe}_{2} \mathrm{O}_{3}$ which possibly originates from the decomposition of $\mathrm{Fe}_{3} \mathrm{O}_{4}$ in the composite under the strong laser light radiation during the Raman measurement ${ }^{40}$. The remaining two characteristic peaks at 1350 and $1590 \mathrm{~cm}^{-1}$ are in good agreement with the typical D band and $\mathrm{G}$ band ${ }^{41,42}$, respectively, which are possibly associated with disordered carbon and the first-order scattering of the $\mathrm{E}_{2 \mathrm{~g}}$ mode of $\mathrm{sp}^{2}$ carbon domains ${ }^{43}$. Here, the dicyandiamide and thiourea hydrothermal reaction and subsequent dehydration heat-treatment processes obviously facilitate the FeOOH particle uniformly attached on graphene ${ }^{38,39}$, Nitrogen and Sulfur co-incorporated graphene, and finally the $\mathrm{Fe}_{3} \mathrm{O}_{4}$ nanoparticle encapsulated into $\mathrm{N}, \mathrm{S}$ co-doped graphene nanosheets. Those $\mathrm{N}-\mathrm{S}-\mathrm{G} / \mathrm{Fe}_{3} \mathrm{O}_{4}$ nanostructures, consisting of uniformly dispersed $\mathrm{Fe}_{3} \mathrm{O}_{4}$ nanoparticles and the encapsulating $\mathrm{N}, \mathrm{S}$ co-doped graphene nanosheets with excellent conductivity, effectively combine the advantages of nanoscale $\mathrm{Fe}_{3} \mathrm{O}_{4}$ particles with those of N, S co-doped graphene mainly due to the particular bi-heteroatom-doped graphene/ $\mathrm{Fe}_{3} \mathrm{O}_{4}$ nanoarchitecture, the uniformly dispersed $\mathrm{Fe}_{3} \mathrm{O}_{4}$ nanoparticles and the encapsulating $\mathrm{N}, \mathrm{S}$ co-doped graphene nanosheets.

The morphologies of the as-prepared graphene, N-S-G/Fe $\mathrm{O}_{4}$ composite, as well as the pure $\mathrm{Fe}_{3} \mathrm{O}_{4}$, have been respectively investigated by the scanning electron microscope (SEM), the field-emission scanning electron microscopy (FE-SEM) and the Transmission electron microscopy (TEM) (see Supporting Information Figure S1 and Fig. 4). As shown in Supporting Information Figure S1(a), the as-prepared graphene nonosheets are randomly stacked up to form fluffy matrix, where there are some wrinkles on the surface of graphene sheets and many meso- or micro- holes/pores in the graphene matrix possibly owing to the rolling up and surrounding effect of graphene planes. Similar phenomenon appears in the as-prepared N-S-G/Fe $\mathrm{O}_{4}$ composite, and there are also many wrinkles on their surface and many meso- or micro- holes/pores in the composite except for many $\mathrm{Fe}_{3} \mathrm{O}_{4}$ nanoparticles obviously dispersed on the surface of N, S co-doped graphene nanosheets (see Supporting Information Figure S1(b)). As depicted in Fig. 4(a,b), there are many $\mathrm{Fe}_{3} \mathrm{O}_{4}$ nanoparticles or nanoparticle aggregates encapsulated into the $\mathrm{N}, \mathrm{S}$ co-doped graphene nanosheets, which not only effectively buffer agglomeration and mechanical strain originating from the large volume variation during the lithiation/delithiation processes but also greatly enhance the conductivity of the composite including both lithium ion conductivity and electron conductivity. In Supporting Information Figure S1 (c,d) and Fig. 4(c,d), the TEM images of the as-prepared N-S-G/ 


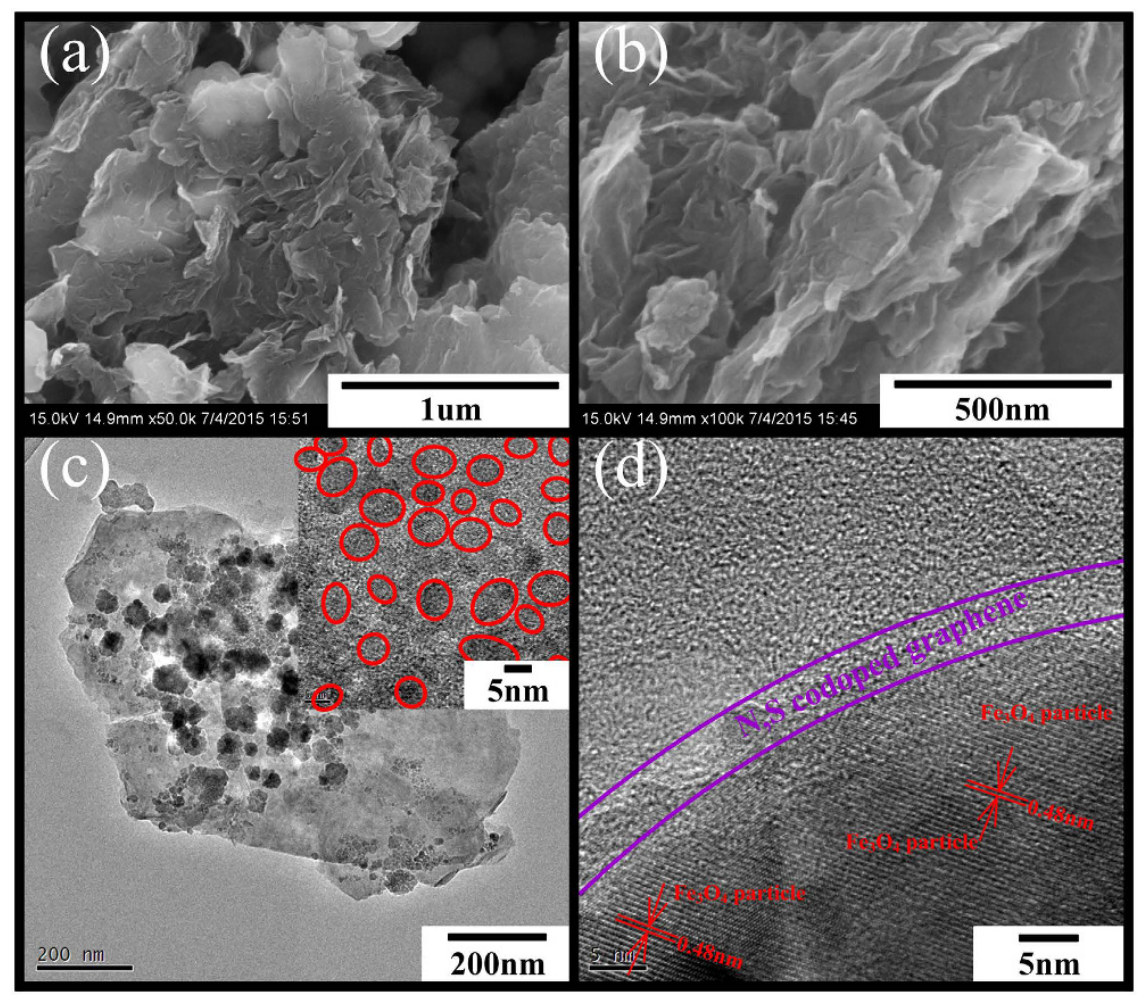

Figure 4. FE-SEM and TEM images of as-prepared N-S-G/Fe $\mathrm{O}_{4}$ composite: (a) FE-SEM image of as-prepared $\mathrm{N}-\mathrm{S}-\mathrm{G} / \mathrm{Fe}_{3} \mathrm{O}_{4}$ composite revealing the $\mathrm{Fe}_{3} \mathrm{O}_{4}$ nanoparticles encapsulated in the $\mathrm{N}, \mathrm{S}$ co-doped graphene nanosheets; (b) high-magnification FE-SEM image of as-prepared N-S-G/ $\mathrm{Fe}_{3} \mathrm{O}_{4}$ composite; (c) TEM image of as-prepared N-S-G/Fe $\mathrm{O}_{4}$ composite indicating that there are many $\mathrm{Fe}_{3} \mathrm{O}_{4}$ nanoparticles distributed and encapsulated in the $\mathrm{N}, \mathrm{S}$ co-doped graphene nanosheets $\left(\mathrm{Fe}_{3} \mathrm{O}_{4}\right.$ nanoparticles with average diameters of $\sim 5-10 \mathrm{~nm}$ are dispersed uniformly in in the N, S co-doped graphene nanosheets, as shown in the Inset); (d) high magnification TEM image of as-prepared N-S-G/Fe $\mathrm{O}_{4}$ composite indicating that the $\mathrm{Fe}_{3} \mathrm{O}_{4}$ nanoparticles are effectively encapsulated into the $\mathrm{N}, \mathrm{S}$ co-doped graphene nanosheets.

$\mathrm{Fe}_{3} \mathrm{O}_{4}$ composite have further shed light on their structural and morphological characteristics. There are many $\mathrm{Fe}_{3} \mathrm{O}_{4}$ nanoparticle aggregates uniformly dispersed on the surface of $\mathrm{N}, \mathrm{S}$ co-doped graphene nanosheets (see Fig. 4(c) and Supporting Information Figure $\mathrm{S} 1(\mathrm{c}, \mathrm{d})$ ), and those $\mathrm{Fe}_{3} \mathrm{O}_{4}$ nanoparticle aggregates with diameters of $\sim 80-100 \mathrm{~nm}$ actually consist of some tiny $\mathrm{Fe}_{3} \mathrm{O}_{4}$ nanoparticles with diameters of $\sim 5-10 \mathrm{~nm}$ aggregated together, respectively (see Fig. 4(c) inset), which are obviously much smaller than the sizes of those pure $\mathrm{Fe}_{3} \mathrm{O}_{4}$ nanoparticles or nanoparticle aggregates (see Supporting Information Figure S1(e,f)). As shown in Fig. 4(d), the high resolution transmission electron microscope (HRTEM) image of the $\mathrm{N}-\mathrm{S}-\mathrm{G} / \mathrm{Fe}_{3} \mathrm{O}_{4}$ composite further demonstrates that the $\mathrm{Fe}_{3} \mathrm{O}_{4}$ in the $\mathrm{N}-\mathrm{S}-\mathrm{G} / \mathrm{Fe}_{3} \mathrm{O}_{4}$ composite consists of many nanoparticles/nanocrystals that are uniformly and tightly attached to the surfaces of the $\mathrm{N}, \mathrm{S}$ co-doped graphene nanosheets to form an encapsulating N-S-G/ $\mathrm{Fe}_{3} \mathrm{O}_{4}$ nanoparticles architecture, except that there are a few $\mathrm{Fe}_{3} \mathrm{O}_{4}$ nanocrystals existed in an aggregate form. In addition, the HRTEM image clarifies the crystal structure with an interplanar spacing of approximately $0.480 \mathrm{~nm}$ between neighboring (111) planes of the cubic spinel $\mathrm{Fe}_{3} \mathrm{O}_{4}$, as those planes were parallel to the electron beam, which is similar to what has been reported previously ${ }^{44}$.

As depicted in Fig. 5, Supporting Information Figures S2 and S3, the X-ray photoelectron spectroscopy (XPS) analysis, the element mapping and the energy dispersive X-ray spectroscopy (EDX) analysis of the N-S-G/Fe $\mathrm{O}_{4}$ composite, as well as the thermogravimetric (TGA) and different scanning calorimetric (DSC) analysis of the $\mathrm{N}-\mathrm{S}-\mathrm{G} / \mathrm{Fe}_{3} \mathrm{O}_{4}$ composite, have been conducted to further explore the composition of the N-S-G/Fe $\mathrm{O}_{4}$ composite, respectively. The XPS analysis of the $\mathrm{N}-\mathrm{S}-\mathrm{G} / \mathrm{Fe}_{3} \mathrm{O}_{4}$ composite not only clearly demonstrates the presence of $\mathrm{Fe}, \mathrm{C}, \mathrm{O}$, $\mathrm{N}$ and $\mathrm{S}$ elements (see Fig. 5(a)) but also discloses the chemical compositions and chemical oxidation states of the $\mathrm{Fe}, \mathrm{C}, \mathrm{O}, \mathrm{N}$ and $\mathrm{S}$ elements in the N-S-G/Fe $\mathrm{O}_{4}$ composite via fitting their own corresponding XPS high-resolution spectra of the Fe2p region, C1s region, O1s region, N1s region and S2p region (see Fig. 5(a) inset and Fig. 5(b-f)), respectively, which is in good accordance with its elemental mapping and EDX result (see Figure S2). The Fe2p spectrum (see Fig. 5(b)) for the N-S-G/Fe $\mathrm{O}_{4}$ composite consists of two symmetrical broadened peaks with the binding energies (BEs) of $710.79 \mathrm{eV}$ and $724.60 \mathrm{eV}$, which are attributable to the Fe2p3/2 and Fe2p1/2, respectively, for both $\mathrm{Fe}^{2+}$ and $\mathrm{Fe}^{3+}$ ions in the $\mathrm{Fe}_{3} \mathrm{O}_{4}$, actually the mixed state of $\mathrm{FeO}$ and $\mathrm{Fe}_{2} \mathrm{O}_{3}$. These values agree very well with the literature values ${ }^{45}$. And the two small satellite peaks of Fe 2p3/2 and Fe2p1/2 at $718.71 \mathrm{eV}$ and $732.72 \mathrm{eV}$ (see Fig. 5(b)) in the N-S-G/Fe $\mathrm{O}_{4}$ composite further reveal the presence of a very small amount of $g-\mathrm{Fe}_{2} \mathrm{O}_{3}{ }^{45}$. The XPS pattern of $\mathrm{Fe} 2 \mathrm{p}$ effectively reveals the existence of iron element in the form of $\mathrm{Fe}_{3} \mathrm{O}_{4}$ for our N-S-G/Fe $\mathrm{O}_{4}$ composite, which is in good agreement with the XRD result of the N-S-G/Fe $\mathrm{O}_{4}$ composite 

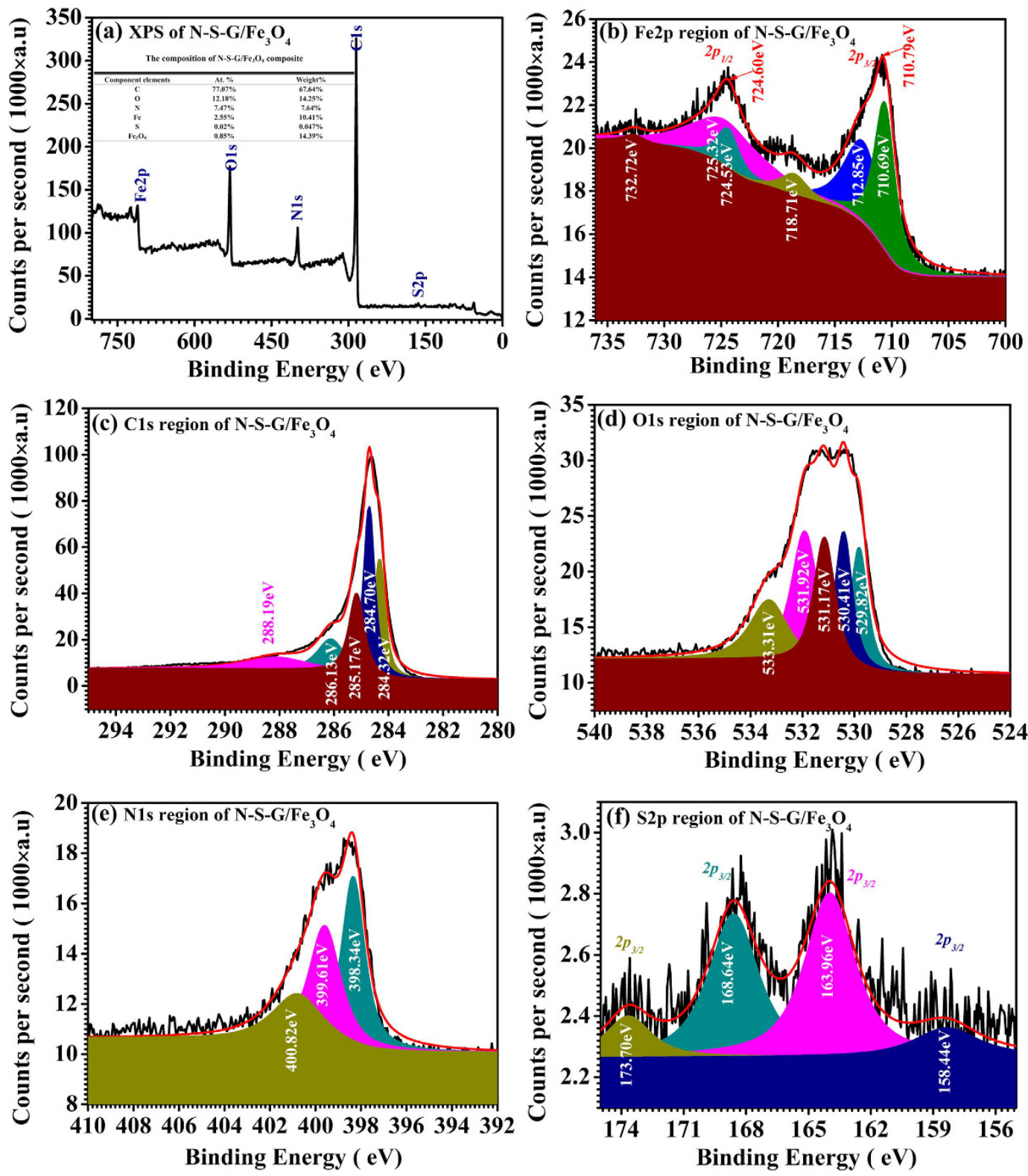

Figure 5. The XPS spectra of N-S-G/Fe $\mathrm{O}_{4}$ composite. (a) Survey spectrum; (b) XPS high-resolution spectra of the Fe2p region; (c) XPS high-resolution spectra of the C1s region; (d) XPS high-resolution spectra of the O1s region; (e) XPS high-resolution spectra of the N1s region; (f) XPS high-resolution spectra of the S2p region.

(see Fig. 1(b)). As shown in Fig. 5(a) inset, the calculated $\mathrm{Fe}_{3} \mathrm{O}_{4}$ content in the composite is 14.39 wt $\%$, agreeing well with what is obtained from the EDX analysis result of the N-S-G/Fe $\mathrm{O}_{4}$ composite (14.825wt\%, Figure S2(h) inset), but much smaller than that from the TGA result (53.37wt\%, Figure S3). The larger difference between the calculated $\mathrm{Fe}_{3} \mathrm{O}_{4}$ content in the composite according to the XPS and the EDX result and that derived from the TGA analysis is possibly due to the cause that the former two means belong to one of surface-testing techniques on material composition while the latter is one of bulk phase-testing techniques. In other words, most of $\mathrm{Fe}_{3} \mathrm{O}_{4}$ in the N-S-G/ $\mathrm{Fe}_{3} \mathrm{O}_{4}$ composite exists in the form of $\mathrm{Fe}_{3} \mathrm{O}_{4}$ nanoparticles encapsulated into the $\mathrm{N}, \mathrm{S}$ co-doped graphene nanosheets, which are in good accordance with the SEM, FE-SEM and TEM results (see Fig. 4 and Figure S1). As for the $\mathrm{C} 1 \mathrm{~s}$ spectrum in the $\mathrm{N}-\mathrm{S}-\mathrm{G} / \mathrm{Fe}_{3} \mathrm{O}_{4}$ composite (see Fig. 5(c)), the two strongest peaks at $284.70 \mathrm{eV}$ and $284.32 \mathrm{eV}$ are attributed to the graphitic carbon in un-oxidized graphitic carbon matrix, whereas the following peak at $285.17 \mathrm{eV}$ is partly attributed to the existence of some nitrogen-containing functional group in organic matrix $(C=N)$ after heat treatment under relative low temperature ${ }^{46,47}$, which is in good accordance with the Nitrogen element mapping result (see Figure S2(e)). The remaining two small peaks at $286.10 \mathrm{eV}$ and $288.19 \mathrm{eV}$ possibly come from a trace amount of carboxyl in the composite sample ${ }^{46,47}$. As shown in Fig. $5(\mathrm{~d})$, the main portion of the $\mathrm{O} 1 \mathrm{~s}$ spectrum response could come from the $\mathrm{Fe}-\mathrm{O}$ bond in the $\mathrm{N}-\mathrm{S}-\mathrm{G} / \mathrm{Fe}_{3} \mathrm{O}_{4}$ composite, as evidenced by O1s binding energy (BE) peak at $\sim 529.82 \mathrm{eV}$ and $530.41 \mathrm{eV}$ (see Fig. 5(d)), which probably arises from the mixed state nature of $\mathrm{FeO}$ and $\mathrm{Fe}_{2} \mathrm{O}_{3}$ for $\mathrm{Fe}_{3} \mathrm{O}_{4}$ in the composite ${ }^{45}$. And those peaks at $531.17 \mathrm{eV}$ and 

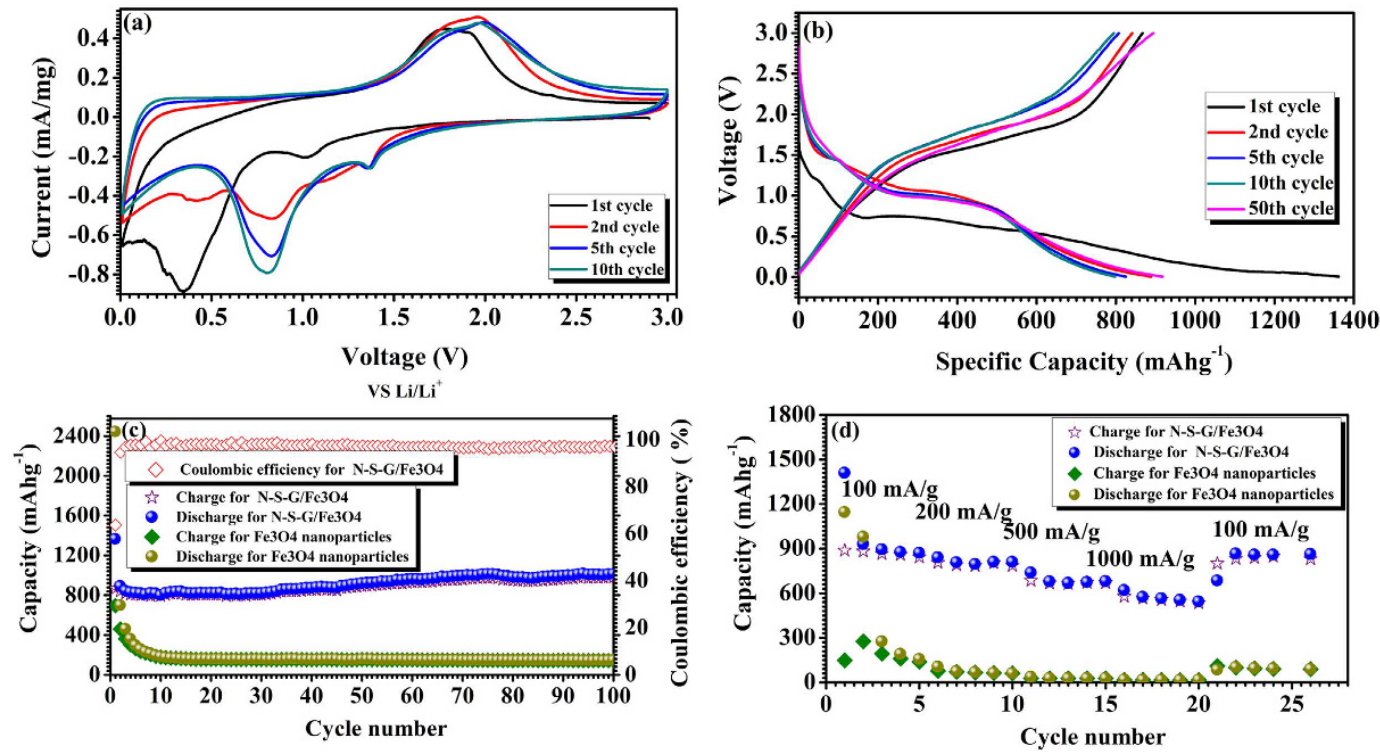

Figure 6. Electrochemical performance of $\mathrm{N}-\mathrm{S}-\mathrm{G} / \mathrm{Fe}_{3} \mathrm{O}_{4}$ composite and $\mathrm{Fe}_{3} \mathrm{O}_{4}$ nanoparticles electrodes cycled between 0.01 and 3.0 V vs. $\mathrm{Li}^{+} / \mathrm{Li}$. (a) Cyclic voltammograms of $\mathrm{N}-\mathrm{S}-\mathrm{G} / \mathrm{Fe}_{3} \mathrm{O}_{4}$ composite electrode of the $1^{\text {st }}, 2^{\text {nd }}, 5^{\text {th }}$ and $10^{\text {th }}$ cycles at a scan rate of $0.1 \mathrm{mVs}^{-1}$ in the voltage range of $0.01-3.0 \mathrm{~V}$. (b) Voltage profiles for selected cycles of N-S-G/Fe $\mathrm{O}_{4}$ composite electrode at the current density of $100 \mathrm{mAg}^{-1}$. (c) Capacity vs. cycle number curves and coulombic efficiency from the first cycle to the $100^{\text {th }}$ cycle for the N-S-G/Fe $\mathrm{O}_{4}$ composite and $\mathrm{Fe}_{3} \mathrm{O}_{4}$ nanoparticles at the current density of $100 \mathrm{mAg}^{-1}$ with cut-off voltage between 0.01 and 3.0 V. (d) Rate capabilities of N-S-G/Fe $\mathrm{F}_{3} \mathrm{O}_{4}$ composite and $\mathrm{Fe}_{3} \mathrm{O}_{4}$ nanoparticles electrodes at various currents $(100 \mathrm{~mA} / \mathrm{g}, 200 \mathrm{~mA} / \mathrm{g}, 500 \mathrm{~mA} / \mathrm{g}, 1000 \mathrm{~mA} / \mathrm{g})$.

$531.13 \mathrm{eV}$ may be due to the $\mathrm{OH}^{-}$radical, adsorbed oxygen, or carbonyl ${ }^{47}$. As for the high $\mathrm{BE}$ peaks at $533.31 \mathrm{eV}$ (Fig. 5(d)), it possibly originates from the absorbed $\mathrm{H}_{2} \mathrm{O}$ outside ${ }^{47}$. As shown in Fig. 5(a) inset, the calculated $\mathrm{N}$ content in the sample is 7.64 at\%, much higher than the EDX result of nitrogen in composite $(2.41 \%)$. And the main fitted N1s peaks at $398.34 \mathrm{eV}$ and $399.16 \mathrm{eV}$ (see Fig. 5(e)) represent pyridinic and pyrrolic types of $\mathrm{N}$ atoms in hybrids ${ }^{46,47}$, respectively, while the remaining fitted N1s peak at $400.82 \mathrm{eV}$ (see Fig. $5(\mathrm{e})$ ) possibly originates from the nitrogen oxide ( $\mathrm{N}-\mathrm{O}$ bond) in the composite ${ }^{47}$. The high-level nitrogen doping and pyridinic-like substructures can provide a feasible pathway for $\mathrm{Li}^{+}$penetration into the graphene-layers, which is beneficial for enhancing the electrochemical performances ${ }^{34,48}$. The weak S2p spectrum (see Fig. 5(f)) for the N-S-G/Fe $\mathrm{O}_{3}$ composite mainly consists of two peaks with the binding energies (BEs) of $163.96 \mathrm{eV}$ and $168.64 \mathrm{eV}$, which are probably attributable to the S2p 3/2 of carbon sulfide (C-S bond) and that of S, O-contained composite (S-O bond ${ }^{47,49,50}$, respectively, while the remaining two satellite peaks with the binding energies (BEs) of $158.44 \mathrm{eV}$ and $173.07 \mathrm{eV}$ are probably attributable to the S2p3/2 of little iron sulfide and that of sulfur oxide ${ }^{47,49,50}$, respectively. From a combination of the XRD, Raman, SEM, FE-SEM and TEM results, as well as the XPS results, it is concluded that the N-S-G/ $\mathrm{Fe}_{3} \mathrm{O}_{4}$ composite mainly consists of many uniformly dispersed $\mathrm{Fe}_{3} \mathrm{O}_{4}$ nanoparticles/ nanocrystals and the $\mathrm{N}, \mathrm{S}$ co-doped graphene nanosheets. The $\mathrm{Fe}_{3} \mathrm{O}_{4}$ nanoparticle/nanocrystals, together with the N, S co-doped graphene nanosheets, effectively form a particular encapsulating N.S co-doped graphene nanosheets $/ \mathrm{Fe}_{3} \mathrm{O}_{4}$ nanoparticles architecture. In addition, there are many meso/micro- holes/voids/pores surrounded by many randomly-aligned N, S co-doped graphene nanosheets. The particular encapsulating N, S co-doped graphene nanosheets $/ \mathrm{Fe}_{3} \mathrm{O}_{4}$ nanoparticles architecture would possess many unique advantages in lithium ion battery application, such as high conductivity owing to encapsulation of $\mathrm{Fe}_{3} \mathrm{O}_{4}$ nanoparticles/nanocrystals into the $\mathrm{N}, \mathrm{S}$ co-doped graphene nanosheets with high conductivity, improved $\mathrm{Li}^{+}$and electrolyte transport in electrode material because of many meso/micro- holes/voids/pores surrounded by many randomly-aligned N, S co-doped graphene nanosheets, enhanced lithium intercalation sites owing to the high-level nitrogen and sulfur doping for the composite and so on, all of which would greatly enhance the electrochemical performance of the electrode.

The electrochemical performances of the N-S-G/Fe $\mathrm{O}_{4}$, reduced graphene oxide $/ \mathrm{Fe}_{3} \mathrm{O}_{4}\left(\mathrm{rGO} / \mathrm{Fe}_{3} \mathrm{O}_{4}\right), \mathrm{N}, \mathrm{S}$ co-doped graphene $/ \mathrm{Fe}_{3} \mathrm{O}_{4}$ composites with low content of $\mathrm{Fe}_{3} \mathrm{O}_{4}$ (L-N-S-G/Fe $\mathrm{O}_{4}$ ), N, S co-doped graphene/ $\mathrm{Fe}_{3} \mathrm{O}_{4}$ composites with high content of $\mathrm{Fe}_{3} \mathrm{O}_{4}$ (H-N-S-G/ $/ \mathrm{Fe}_{3} \mathrm{O}_{4}$ ) and $\mathrm{Fe}_{3} \mathrm{O}_{4}$ nanoparticles electrodes including the galvanostatic discharge-charge cycling and Cyclic Voltammetry have systematically been evaluated (see Fig. 6 and Supporting Information Figure S4). The cyclic voltammograms (CVs) of the N-S-G/Fe $\mathrm{O}_{4}$ composite electrode including the $1^{\text {st }}, 2^{\text {nd }}, 5^{\text {th }}$ and $10^{\text {th }}$ cycles at a scan rate of $0.1 \mathrm{mVs}^{-1}$ with the cutoff voltages between 0.01 and $3.0 \mathrm{~V}$ were obtained and are plotted in Fig. 6(a), respectively. The curves of the initial few cycles are different from the later ones, especially with respect to the rapid disappearance of the obvious cathodic peak at $0.3447 \mathrm{~V}$, which is probably ascribed to the conversion reaction that results in the formation of $\mathrm{Li}_{2} \mathrm{O}$ and iron ${ }^{51,52}$. In the subsequent cycles, this peak shifts to higher voltage $0.8218 \mathrm{~V}$, indicating that there is some structural variation in the N-S-G/ $\mathrm{Fe}_{3} \mathrm{O}_{4}$ composite electrode after lithium ion insertion in the first cycle. This is further evidenced by the $\mathbf{C V}$ result 
of the pure $\mathrm{Fe}_{3} \mathrm{O}_{4}$ electrode (see Figure $\mathrm{S} 4(\mathrm{a})$ ) as well as that of $\mathrm{rGO} / \mathrm{Fe}_{3} \mathrm{O}_{4}$ composite (Figure $\mathrm{S} 4(\mathrm{~b})$ ). As shown in Figure S4(a), the cathodic peak at $0.2838 \mathrm{~V}$ in the first cycle shifts to higher voltage $0.6255 \mathrm{~V}$ in the subsequent cycles, which is also possibly attributable to the structural variation in the pure $\mathrm{Fe}_{3} \mathrm{O}_{4}$ composite electrode after lithium ion insertion in the first cycle. The similar phonomenon observed in the $\mathrm{rGO} / \mathrm{Fe}_{3} \mathrm{O}_{4}$ composite sample (Figure S4(b)) except that the cathodic peak at $0.4323 \mathrm{~V}$ in the first cycle shifts to higher voltage $0.7097 \mathrm{~V}$ in the subsequent cycles. And the obvious decrease of peak intensity reveals the irreversible lithium ion capacity loss possibly owing to the formation of an inactive solid-electrolyte interphase (SEI) during the first cycle ${ }^{51-54}$. From the fifth cycle, stable cathodic/anodic peak pair at $0.8218 \mathrm{~V}$ and $1.9 \mathrm{~V}$ in the $\mathrm{N}-\mathrm{S}-\mathrm{G} / \mathrm{Fe}_{3} \mathrm{O}_{4}$ composite electrode (Fig. 6(a)) and that at $0.6255 \mathrm{~V}$ and $1.5653 \mathrm{~V}$ in the pure $\mathrm{Fe}_{3} \mathrm{O}_{4}$ electrode (Figure S4(a)), as well as that at $0.7097 \mathrm{~V}$ and $1.8314 \mathrm{~V}$ in the $\mathrm{rGO} / \mathrm{Fe}_{3} \mathrm{O}_{4}$ electrode (Figure $\mathrm{S} 4(\mathrm{~b})$ ), belong to the characteristic cathodic/anodic peak pair of the $\mathrm{Fe}_{3} \mathrm{O}_{4}$-based electrode ${ }^{51-54}$. Additionally, with the increase of the cycle number, there is a slight shift of the cathodic/anodic peak pair in the N-S-G/ $\mathrm{Fe}_{3} \mathrm{O}_{4}$ composite electrode (Fig. 6(a)) and in the $\mathrm{rGO} / \mathrm{Fe}_{3} \mathrm{O}_{4}$ composite electrode, which is probably ascribed to the superposition effect of the characteristic cathodic/anodic peak pair from the $\mathrm{N}, \mathrm{S}$ co-doped graphene and reduced graphene and that from $\mathrm{Fe}_{3} \mathrm{O}_{4}$ in composite.

The cycling performance of the N-S-G/ $\mathrm{Fe}_{3} \mathrm{O}_{4}, \mathrm{rGO} / \mathrm{Fe}_{3} \mathrm{O}_{4}, \mathrm{~L}-\mathrm{N}-\mathrm{S}-\mathrm{G} / \mathrm{Fe}_{3} \mathrm{O}_{4}, \mathrm{H}-\mathrm{N}-\mathrm{S}-\mathrm{G} / \mathrm{Fe}_{3} \mathrm{O}_{4}$ composite electrodes, as well as that of $\mathrm{Fe}_{3} \mathrm{O}_{4}$ nanoparticles electrode were further probed in the voltage range of 3.0-0.01 V (vs. $\mathrm{Li} / \mathrm{Li}^{+}$) at a constant current density of approximately $100 \mathrm{mAg}^{-1}$ up to 100 cycles. Figure 6(b) reveals the voltage profiles of $\mathrm{N}-\mathrm{S}-\mathrm{G} / \mathrm{Fe}_{3} \mathrm{O}_{4}$ composite electrode at the current density of $100 \mathrm{mAg}^{-1}$. The first discharge and charge steps deliver a specific capacity of 1362.2 and $867.3 \mathrm{mAh} / \mathrm{g}$, respectively, while the pure $\mathrm{Fe}_{3} \mathrm{O}_{4}$ and $\mathrm{rGO} /$ $\mathrm{Fe}_{3} \mathrm{O}_{4}$ composites electrode does the 2443.1 and $696.1 \mathrm{mAhg}^{-1}, 1585.7$ and $987.4 \mathrm{mAhg}^{-1}$ in the first discharge and charge steps (see Figure S4(c,d)). The initial coulombic efficiency of the N-S-G/Fe $\mathrm{O}_{4}$ composite electrode is above $63.6 \%$, greatly higher than that of the pure $\mathrm{Fe}_{3} \mathrm{O}_{4}$ electrode $(28.7 \%)$ and some slightly higher than that of $\mathrm{rGO} / \mathrm{Fe}_{3} \mathrm{O}_{4}$ composites electrode (62.2\%), which is possibly due to the encapsulation of the $\mathrm{N}, \mathrm{S}$ co-doped graphene nanosheets and their conductivity enhancement in lithium ions and electrons ${ }^{8,55}$. Figure $6(\mathrm{c})$ indicates the curves of the charge/discharge capacity versus the cycle number and the coulombic efficiency for the $\mathrm{N}-\mathrm{S}-\mathrm{G} / \mathrm{Fe}_{3} \mathrm{O}_{4}$ composite electrode and pure $\mathrm{Fe}_{3} \mathrm{O}_{4}$ electrode at the current density of $100 \mathrm{mAg}^{-1}$, respectively. The $\mathrm{N}-\mathrm{S}-\mathrm{G} / \mathrm{Fe}_{3} \mathrm{O}_{4}$ composite electrode exhibits excellent cycling performance and a high reversible specific capacity of over $854 \mathrm{mAhg}^{-1}$ after the first 10 cycles. Moreover, it rises up slowly to a reversible capacity of approximately $1034.33 \mathrm{mAhg}^{-1}$ after 70 cycles and maintains a reversible capacity of approximately $1055.20 \mathrm{mAhg}^{-1}$ after 100 cycles with the coulombic efficiency of nearly $100 \%$, not only much higher than the specific capacity of pure $\mathrm{Fe}_{3} \mathrm{O}_{4}$ nanoparticles $\left(148.38 \mathrm{mAhg}^{-1}\right.$, see Fig. 6(c)) after 100 cycles, but also higher than those of the $\mathrm{rGO} / \mathrm{Fe}_{3} \mathrm{O}_{4}\left(758.5 \mathrm{mAhg}^{-1}\right.$, see Figure S4(e)), L-N-S-G/Fe $\mathrm{O}_{4}\left(568.2 \mathrm{mAhg}^{-1}\right.$, see Figure S4(f)), H-N-S-G/Fe $\mathrm{O}_{4}$ (581.6mAhg ${ }^{-1}$, see Figure S4(f)) composite. When compared with that for pure $\mathrm{Fe}_{3} \mathrm{O}_{4}$ electrode, the greatly enhancement in the lithium ion storage capacity for the $\mathrm{N}-\mathrm{S}-\mathrm{G} / \mathrm{Fe}_{3} \mathrm{O}_{4}$ composite electrode is mainly attributed to the short lithium ion diffusion paths, easy access of the electrolyte through the meso/micro-pores surrounded by the randomly-aligned N, S co-doped graphene nanosheets, as well as the good electrical connectivity. As compared with the $\mathrm{rGO} / \mathrm{Fe}_{3} \mathrm{O}_{4}, \mathrm{~L}-\mathrm{N}-\mathrm{S}-\mathrm{G} / \mathrm{Fe}_{3} \mathrm{O}_{4}$ and $\mathrm{H}-\mathrm{N}-\mathrm{S}-\mathrm{G} / \mathrm{Fe}_{3} \mathrm{O}_{4}$, respectively, the greatly enhancement in the lithium ion storage capacity for the $\mathrm{N}-\mathrm{S}-\mathrm{G} / \mathrm{Fe}_{3} \mathrm{O}_{4}$ composite electrode is possibly attributed to nature of $\mathrm{N}$, $\mathrm{S}$ co-doped graphene nanosheets with good electrical conductivity and high lithium ion storage, an appropriate amount of $\mathrm{Fe}_{3} \mathrm{O}_{4}$ nanoparticles in the composite and fully encapsulated $\mathrm{Fe}_{3} \mathrm{O}_{4}$ nanoparticles into $\mathrm{N}$, $\mathrm{S}$ co-doped graphene nanosheets, respectively, which all together results in high lithium ion storage capacity for the N-S-G/ $\mathrm{Fe}_{3} \mathrm{O}_{4}$ composite electrode. As demonstrated in Fig. 6(d), excellent rate performance has been acquired for the $\mathrm{N}-\mathrm{S}-\mathrm{G} / \mathrm{Fe}_{3} \mathrm{O}_{4}$ composite electrode. The composite electrode delivers a discharge capacity of over $876.2 \mathrm{mAhg}^{-1}$ at the current density of $100 \mathrm{mAg}^{-1}, 820.31 \mathrm{mAhg}^{-1}$ at $200 \mathrm{mAg}^{-1}, 688.87 \mathrm{mAhg}^{-1}$ at $500 \mathrm{mAg}^{-1}, 556.69 \mathrm{mAhg}^{-1}$ at $1000 \mathrm{mAg}^{-1}$, respectively, finally recovers to around $886.02 \mathrm{mAhg}^{-1}$ when the current density goes back to $100 \mathrm{mAg}^{-1}$, which is not only much better than that for the pure $\mathrm{Fe}_{3} \mathrm{O}_{4}$ electrode, but also than those of the rGO/ $\mathrm{Fe}_{3} \mathrm{O}_{4}$ (Figure $\mathrm{S} 1(\mathrm{~g})$ ), L-N-S-G/Fe $\mathrm{O}_{4}$ and $\mathrm{H}-\mathrm{N}-\mathrm{S}-\mathrm{G} / \mathrm{Fe}_{3} \mathrm{O}_{4}$ (Figure S2(h)) composite electrodes. In order to make clear the electrochemical nature of the N-S-G/ $\mathrm{Fe}_{3} \mathrm{O}_{4}$ composite and pure $\mathrm{Fe}_{3} \mathrm{O}_{4}$ electrodes, as depicted in Figure S5, the electrochemical impedance spectroscopy (EIS) patterns of the N-S-G/ $\mathrm{Fe}_{3} \mathrm{O}_{4}$ composite electrode, as well as that of the pure $\mathrm{Fe}_{3} \mathrm{O}_{4}$ electrode, were obtained in the frequency range $100 \mathrm{kHz}$ to $0.01 \mathrm{~Hz}$ with an amplitude of $10 \mathrm{mV}$. Additionally, the table of the fitted kinetic parameters was inserted into the Nyquist plots. As compared with those of the pure $\mathrm{Fe}_{3} \mathrm{O}_{4}$ electrode, the smaller Rell and Rsl1 of the N-S-G/ $\mathrm{Fe}_{3} \mathrm{O}_{4}$ composite electrode represent its smaller ohmic resistance of the battery cell, resistance of SEI film for the N-S-G/Fe $\mathrm{O}_{4}$ composite electrode, respectively. Therefore, the great enhancement of coulombic efficiency, reversible discharge capacity, and rate capability for the $\mathrm{N}-\mathrm{S}-\mathrm{G} / \mathrm{Fe}_{3} \mathrm{O}_{4}$ composite electrode is probably attributed to the nanosize-encapsulation of $\mathrm{Fe}_{3} \mathrm{O}_{4}$ nanoparticles/nanocrystals in the composite and the porous nature (see Fig. 3), as well as the high conductivity owing to N, S co-doped graphene nanosheets distributing uniformly in the composite.

\section{Discussion}

The charge diffusion mechanism of the N-S-G/Fe $\mathrm{O}_{4}$ composite electrode is depicted in Figure S6 (Supporting Information). Many $\mathrm{Fe}_{3} \mathrm{O}_{4}$ nanoparticles encapsulated into the $\mathrm{N}, \mathrm{S}$ co-doped graphene nanosheets are uniformly attached on the surface of the $\mathrm{N}, \mathrm{S}$ co-doped graphene nanosheets and form a particular architecture with uniformly dispersed $\mathrm{Fe}_{3} \mathrm{O}_{4}$ nanoparticles and N.S co-doped graphene encapsulant. Many meso/micro-pores were surrounded by many randomly-aligned $\mathrm{N}, \mathrm{S}$ co-doped graphene nanosheets. This particular architecture with $\mathrm{Fe}_{3} \mathrm{O}_{4}$ nanoparticles and N.S co-doped graphene encapsulant, the porous nature with many meso/micropores surrounded by randomly-aligned N, S co-doped graphene nanosheets, and the high specific surface area effectively enlarges the electrode-electrolyte contact, shorten the lithium ion diffusion pathways during the discharge/charge cycling and greatly enhance the lithium storage capacity and rate capability. Additionally, the N, S co-doped graphene encapsulant doped with high-content heteroatom in the N-S-G/Fe $\mathrm{O}_{4}$ composite would not 
only greatly enhance the conductivity of the active material during the lithium intercalation/de-intercalation but also increase the charged sites and the lithium capacity ${ }^{34,35}$, which plays an essential role in the excellent lithium storage capacity, cyclability, and rate capability of this electrode.

In summary, particular $\mathrm{N}, \mathrm{S}$ co-doped graphene $/ \mathrm{Fe}_{3} \mathrm{O}_{4}$ architectures, consisting of uniformly dispersed $\mathrm{Fe}_{3} \mathrm{O}_{4}$ nanoparticles and N.S co-doped graphene encapsulant, have been successfully synthesized by a simple hydrothermal process, followed by a subsequent carbonization treatment. As one kind of potential anode material for lithium ion batteries, the $\mathrm{N}-\mathrm{S}-\mathrm{G} / \mathrm{Fe}_{3} \mathrm{O}_{4}$ composite electrode exhibits a high initial reversible capacity of $1362.2 \mathrm{mAhg}^{-1}$ with the coulombic efficiency of approximately $63.6 \%$ at the current density of $100 \mathrm{mAg}^{-1}$. In addition, it delivers a high reversible specific capacity of over $854 \mathrm{mAhg}^{-1}$ after the first 10 cycles, further maintains a reversible capacity of approximately $1055.20 \mathrm{mAhg}^{-1}$ after 100 cycles with the coulombic efficiency of nearly $100 \%$, much higher than that of the pure $\mathrm{Fe}_{3} \mathrm{O}_{4}$ electrode. The composite also exhibits good rate performance with specific capacity of $556.69 \mathrm{mAhg}^{-1}$ when cycled at the current density of $1000 \mathrm{mAg}^{-1}$. This particular composite architecture is characterized by having many meso/micro holes/pores surrounded by many randomly-aligned N, S co-doped graphene nanosheets. Those meso/micro holes/pores facilitate the lithium ion and electrolyte diffusion in these active materials during the charge/discharge processes. Furthermore, the essential N, S co-doped graphene nanosheets in the composite exert many important effects on encapsulating the $\mathrm{Fe}_{3} \mathrm{O}_{4}$ nanoparticles, greatly enhancing the conductivity of the active material, and increasing lithium intercalation sites owing to the high-level nitrogen and sulfur doping in the composite, as compared with the pure $\mathrm{Fe}_{3} \mathrm{O}_{4}$. Therefore, the composite is one of the most promising candidates as the potential anode material for LIBs, even though the composition and structure of those materials require further improvement.

\section{Methods}

Synthesis of $\mathbf{N}, \mathbf{S}$ co-doped graphene/ $\mathrm{Fe}_{3} \mathrm{O}_{4}$ nanostructures. $\quad \mathrm{N}, \mathrm{S}$ co-doped graphene/ $\mathrm{Fe}_{3} \mathrm{O}_{4}$ nanostructures $\left(\mathrm{N}-\mathrm{S}-\mathrm{G} / \mathrm{Fe}_{3} \mathrm{O}_{4}\right)$ have been synthesized by a hydrothermal process, followed by a subsequent carbonization treatment. Firstly, the graphene oxide (GO) was obtained from oxidizing the graphite powder by a modified Hummers'method $^{56}$, followed by two-hour sonication and centrifugation at the rate of $4000 \mathrm{rpm}$ for $10 \mathrm{~min}$ to remove the aggregates and then $1 \mathrm{mg} / \mathrm{ml} \mathrm{GO}$ solution was gained. Subsequently, $3.33 \mathrm{~g}$ dicyandiamide $(99.9 \%$ Sigma-Aldrich), 336mg thiourea (99\% Sigma-Aldrich), and $142.2 \mathrm{mg} \mathrm{FeCl}_{2} \cdot 4 \mathrm{H}_{2} \mathrm{O}$ (Analytical Pure, Sinopharm Chemical Reagent Co. Ltd, China) were dispersed into $88 \mathrm{ml} \mathrm{GO}$ suspension. After stirring vigorously for $1 \mathrm{~h}$, the resulting solution was transferred into a $100 \mathrm{ml}$ Teflon-lined stainless steel autoclave, sealed and further heated at $150^{\circ} \mathrm{C}$ for $12 \mathrm{~h}$. After filtering, the solid products were obtained, and washed with deionized water several times to remove the remaining ions. The as-obtained dark grey products were dried at $60^{\circ} \mathrm{C}$ in air for $12 \mathrm{~h}$ and then transferred to a ceramic crucible and carbonized at $500^{\circ} \mathrm{C}$ for $2 \mathrm{~h}$ under nitrogen atmosphere. Finally, some dark N, S co-doped graphene $/ \mathrm{Fe}_{3} \mathrm{O}_{4}$ powder was obtained and marked as $\mathrm{N}-\mathrm{S}-\mathrm{G} / \mathrm{Fe}_{3} \mathrm{O}_{4}$. For comparison, the $\mathrm{rGO} / \mathrm{Fe}_{3} \mathrm{O}_{4}$ was also prepared in the same condition in the absence of dicyandiamide and thiourea while the composites with different content of $\mathrm{Fe}_{3} \mathrm{O}_{4}$ were further synthesized in the same way via introducing different content of $\mathrm{FeCl}_{2} \cdot 4 \mathrm{H}_{2} \mathrm{O}$ precursor $(71.1 \mathrm{mg}$ and $284.4 \mathrm{mg}$ ) during the synthesis procedure, marked as L-N-S-G/ $\mathrm{Fe}_{3} \mathrm{O}_{4}$ and $\mathrm{H}-\mathrm{N}-\mathrm{S}-\mathrm{G} / \mathrm{Fe}_{3} \mathrm{O}_{4}$, respectively. Some $\mathrm{Fe}_{3} \mathrm{O}_{4}$ powder was simply prepared by the liquid precipitation reaction (LPR). Typically, $176 \mathrm{mg} \mathrm{FeCl}{ }_{3} \cdot 6 \mathrm{H}_{2} \mathrm{O}$ and $130 \mathrm{mg} \mathrm{FeCl} \cdot 4 \mathrm{H}_{2} \mathrm{O}\left(\mathrm{Fe}^{3+}\right.$ and $\mathrm{Fe}^{2+}$ with a mole ratio of 1:1) were dispersed in $50 \mathrm{~mL}$ deionized water. After $1 \mathrm{M} \mathrm{NaOH}$ aqueous solution was dropped by drop added into the suspension until the $\mathrm{pH} \approx 11$, the mixture was stirred for $2 \mathrm{~h}$ at $80^{\circ} \mathrm{C}$ in air. The dark products were cooled and washed several times with deionized water for several times and dried at $60^{\circ} \mathrm{C}$ under vacuum environment.

Materials Characterization. Thermogravimetric analysis (TGA) of the as-prepared N, S co-doped graphene $/ \mathrm{Fe}_{3} \mathrm{O}_{4}$ nanocomposite was carried out with a TGA/DSC1 type instrument (TGA/DSC1 SF/1382, Mettler Switzerland, German) with a heating rate of $10^{\circ} \mathrm{C} \mathrm{min}^{-1}$ from room temperature to $1000^{\circ} \mathrm{C}$ in air. The phase of the products was examined with an X' Pert Pro MPD X-ray diffractometer with $\mathrm{Cu}$ K $\alpha$ radiation ( $\lambda=1.5418 \AA$, Philips, Holland). The morphology of these nanomaterials was evaluated with S-3000 scanning electron microscope (SEM, S-3000, HITACHI, Japan), NanoSEM 230 field emission scanning electron microscope (FE-SEM, Nova NanoSEM 230, FEI, America) and a Tecnai G2F20 S-TWIN transmission electron microscope (TEM, Tecnai GX F20 S-TWIN, FEI, America). The X-ray photoelectron spectroscopy (XPS) experiments were carried out on a VG Scientific ESCALAB 250 instrument (XPS, ESCALAB 250, Thermo Scientific, America) by using aluminum K $\alpha$ X-ray radiation during XPS analysis. The Raman spectra were obtained on a Renishaw Invia Raman microscope excited by an argon ion laser beam $(514.5 \mathrm{~nm}, 20 \mathrm{~mW})$.

Electrochemical Characterization. The electrochemical properties were further measured with electrodes that were prepared by compressing a mixture of the as-prepared active materials $\left(\mathrm{Fe}_{3} \mathrm{O}_{4}\right.$ nanopowders or N, S co-doped graphene/ $\mathrm{Fe}_{3} \mathrm{O}_{4}$ nanocomposites), carbon black (Super P, MMM, Belgium), and poly (vinyl difluoride) (PVDF) binder in a weight ratio of 70:15:15, and further coating the mixture onto one piece of copper foil. Pure lithium metal foil was used for the counter and reference electrode. The electrolyte was $\operatorname{LiPF}_{6}(1 \mathrm{M})$ in a mixture of ethylene carbonate (EC) and dimethyl carbonate (DMC) (1:1 v/v; MERCK KgaA, Germany). Coin cells were assembled in a high-purity argon-filled glove box. The galvanostatic method was utilized to measure the electrochemical capacity of the electrodes at room temperature on a LAND-CT2011A instrument with a charge-discharge current density of $100 \mathrm{mAg}^{-1}$. Rate capability tests of the electrodes were then carried out systematically at various current densities $\left(100 \mathrm{mAg}^{-1}, 200 \mathrm{mAg}^{-1}, 500 \mathrm{mAg}^{-1}, 1000 \mathrm{mAg}^{-1}\right)$. The cutoff potentials for charge and discharge in the cycling and rate tests were all set at 3.0 and $0.01 \mathrm{~V}$ versus $\mathrm{Li}^{+} / \mathrm{Li}$, respectively. Cyclic-Voltammetry was performed on a CHI650D electrochemical workstation with the cutoff voltage range between 0.01-3.0 V. Electrochemical impedance spectroscopy (EIS) patterns were recorded using a CHI6500D electrochemical working station in the frequency range $100 \mathrm{kHz}$ to $0.01 \mathrm{~Hz}$ with an amplitude of $10 \mathrm{mV}$. 


\section{References}

1. Taberna, L., Mitra, S., Poizot, P., Simon, P. \& Tarascon, J. M. High rate capabilities $\mathrm{Fe}_{3} \mathrm{O}_{4}$-based Cu nano-architectured electrodes for lithium-ion battery applications. Nat. Mater. 5, 567-573 (2006).

2. Magasinski, A. et al. High-performance lithium-ion anodes using a hierarchical bottom-up approach. Nat. Mater. 9, 353-358 (2010).

3. Zhao, M. Q. et al. Unstacked double-layer templated graphene for high-rate lithium-sulphur batteries. Nat. Commun. 5, 3410 (2014).

4. Wang, Z. Y. et al. Enhancing lithium-sulphur battery performance by strongly binding the discharge products on aminofunctionalized reduced graphene oxide. Nat. Commun. 5, 5002 (2014).

5. Kang, B. \& Ceder, G. Battery materials for ultrafast charging and discharging. Nature 458, 190-193 (2009).

6. Vinayan, B. P. \& Ramaprabhu, S. Facile synthesis of $\mathrm{SnO}_{2}$ nanoparticles dispersed nitrogen doped graphene anode material for ultrahigh capacity lithium ion battery applications. J. Mater. Chem. A 1, 3865-3871 (2013).

7. Cui, L. F., Yang, Y., Hsu, C. M. \& Cui, Y. Carbon-Silicon Core-Shell Nanowires as High Capacity Electrode for Lithium Ion Batteries. Nano Lett. 9, 3370-3374 (2009).

8. Xu, C., Sun, J. \& Gao, L. Controllable synthesis of monodisperse ultrathin $\mathrm{SnO}_{2}$ nanorods on nitrogen-doped graphene and its ultrahigh lithium storage properties. Nanoscale 4, 5425-5430 (2012).

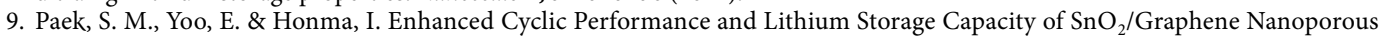
Electrodes with Three-Dimensionally Delaminated Flexible Structure. Nano Lett. 9, 72-75 (2009).

10. Ko, S., Lee, J. I., Yang, H. S., Park, S. \& Jeong, U. Mesoporous CuO Particles Threaded with CNTs for High-Performance Lithium-Ion Battery Anodes. Adv. Mater. 24, 4451-4456 (2012).

11. Zhao, X., Xia, D. \& Zheng, K. $\mathrm{Fe}_{3} \mathrm{O}_{4} / \mathrm{Fe} /$ Carbon Composite and Its Application as Anode Material for Lithium-Ion Batteries. ACS Appl. Mater. Inter. 4, 1350-1356 (2012).

12. Wang, Y. R. et al. One-Pot Magnetic Field Induced Formation of $\mathrm{Fe}_{3} \mathrm{O}_{4} / \mathrm{C}$ Composite Microrods with Enhanced Lithium Storage Capability. Small 10, 2815-2819 (2014).

13. Bhuvaneswari, S. et al. Efficient reduced graphene oxide grafted porous $\mathrm{Fe}_{3} \mathrm{O}_{4}$ composite as a high performance anode material for Li-ion batteries. Phys. Chem. Chem. Phys. 16, 5284-5294 (2014).

14. Lee, S. H. et al. Self-Assembled $\mathrm{Fe}_{3} \mathrm{O}_{4}$ Nanoparticle Clusters as High-Performance Anodes for Lithium Ion Batteries via Geometric Confinement. Nano Lett. 13, 4249-4256 (2013).

15. Luo, J. S. et al. Three-Dimensional Graphene Foam Supported $\mathrm{Fe}_{3} \mathrm{O}_{4}$ Lithium Battery Anodes with Long Cycle Life and High Rate Capability. Nano Lett. 13, 6136-6143 (2013).

16. Wu, Y., Wei, Y., Wang, J. P., Jiang, K. L. \& Fan, S. S. Conformal $\mathrm{Fe}_{3} \mathrm{O}_{4}$ Sheath on Aligned Carbon Nanotube Scaffolds as HighPerformance Anodes for Lithium Ion Batteries. Nano Lett. 13, 818-823 (2013).

17. Luo, H., Huang, K., Sun, B. \& Zhong, J. X. Strategy to Synthesize $\mathrm{Fe}_{3} \mathrm{O}_{4} / \mathrm{C}$ Nanotubes as Anode Material for Advanced Lithium-Ion Batteries. Electrochim. Acta 149, 11-17 (2014).

18. Qu, Q. T. et al. Strongly coupled 1D sandwich-like $\mathrm{C} @ \mathrm{Fe}_{3} \mathrm{O}_{4} @ \mathrm{C}$ coaxial nanotubes with ultrastable and high capacity for lithium-ion batteries. J. Mater. Chem. A 3, 18289-18295 (2015).

19. Shi, Y., Shi, M. M., Qiao, Y. Q., Tu, J. P. \& Chen, H. Z. $\mathrm{Fe}_{3} \mathrm{O}_{4}$ nanobelts: one-pot and template-free synthesis, magnetic property, and application for lithium storage. Nanotechnology 23, 395601 (2012).

20. Xie, W. H. et al. N-Doped Amorphous Carbon Coated $\mathrm{Fe}_{3} \mathrm{O}_{4} / \mathrm{SnO}_{2}$ Coaxial Nanofibers as a Binder-Free Self-Supported Electrode for Lithium Ion Batteries. ACS Appl. Mater. Inter. 6, 20334-20339 (2014).

21. Wang, L., Yu, Y., Chen, P. C., Zhang, D. W. \& Chen, C. H. Electrospinning synthesis of C/Fe $\mathrm{O}_{4}$ composite nanofibers and their application for high performance lithium-ion batteries. J. Power Sources 183, 717-723 (2008).

22. Wei, W. et al. 3D Graphene Foams Cross-linked with Pre-encapsulated $\mathrm{Fe}_{3} \mathrm{O}_{4}$ Nanospheres for Enhanced Lithium Storage. $A d v$. Mater. 25, 2909-2914 (2013).

23. Lim, B. et al. $\mathrm{Fe}_{3} \mathrm{O}_{4}$ nanosphere@microporous organic networks: enhanced anode performances in lithium ion batteries through carbonization. Chem. Commun. 50, 7723-7726 (2014).

24. Luo, Y. et al. Sulfurization of FeOOH nanorods on a carbon cloth and their conversion into $\mathrm{Fe}_{2} \mathrm{O}_{3} / \mathrm{Fe}_{3} \mathrm{O}_{4}-\mathrm{S}$ core-shell nanorods for lithium storage. Chem. Commun. 51, 13016-13019 (2015).

25. Zhou, Q. et al. Low temperature plasma synthesis of mesoporous $\mathrm{Fe}_{3} \mathrm{O}_{4}$ nanorods grafted on reduced graphene oxide for high performance lithium storage. Nanoscale 6, 2286-2291 (2014).

26. Fan, X. Y., Li, S. H., Zhou, H. H. \& Lu, L. One-pot high temperature hydrothermal synthesis of $\mathrm{Fe}_{3} \mathrm{O}_{4} @ \mathrm{C} /$ graphene nanocomposite as anode for high rate lithium ion battery. Electrochim. Acta 180, 1041-1049 (2015).

27. Chen, G. et al. Solvothermal route based in situ carbonization to $\mathrm{Fe}_{3} \mathrm{O}_{4} @ \mathrm{C}$ as anode material for lithium ion battery. Nano Energy 8 , 126-132 (2014).

28. Ke, F. S. et al. Negative electrode comprised of $\mathrm{Fe}_{3} \mathrm{O}_{4}$ nanoparticles and Cu nanowires for lithium ion batteries. Solid State Ionics 262, 18-21 (2014).

29. Zhang, W. M., Wu, X. L., Hu, J. S., Guo, Y. G. \& Wan, L. J. Carbon Coated $\mathrm{Fe}_{3} \mathrm{O}_{4}$ Nanospindles as a Superior Anode Material for Lithium-Ion Batteries. Adv. Funct. Mater. 18, 3941-3946 (2008).

30. Yang, S. L. et al. Improving the electrochemical performance of $\mathrm{Fe}_{3} \mathrm{O}_{4}$ nanoparticles via a double protection strategy through carbon nanotube decoration and graphene networks. Nano Research 8, 1339-1347 (2015).

31. Li, X. Y. et al. Synthesis of 3D Hierarchical $\mathrm{Fe}_{3} \mathrm{O}_{4} /$ Graphene Composites with High Lithium Storage Capacity and for Controlled Drug Delivery. J. Phys. Chem. C 115, 21567-21573 (2011).

32. Ye, J., Zhang, J., Wang, F., Su, Q. \& Du, G. One-pot synthesis of $\mathrm{Fe}_{2} \mathrm{O}_{3}$ /graphene and its lithium-storage performance. Electrochim. Acta 113, 212-217 (2013).

33. Yang, S., Feng, X., Ivanovici, S. \& Muellen, S. K. Fabrication of Graphene-Encapsulated Oxide Nanoparticles: Towards HighPerformance Anode Materials for Lithium Storage. Angew. Chem. Int. Edit. 49, 8408-8411 (2010).

34. Tang, C. et al. Nitrogen-Doped Aligned Carbon Nanotube/Graphene Sandwiches: Facile Catalytic Growth on Bifunctional Natural Catalysts and Their Applications as Scaffolds for High-Rate Lithium-Sulfur Batteries. Adv. Mater. 26, 6100-6105 (2014).

35. Wang, C. et al. High sulfur loading composite wrapped by 3D nitrogen-doped graphene as a cathode material for lithium-sulfur batteries. J. Mater. Chem. A, 2, 5018-5023 (2014).

36. Sandoval, S. et al. Enhanced Thermal Oxidation Stability of Reduced Graphene Oxide by Nitrogen Doping. Chem. Eur. J. 20, 11999-12003 (2014).

37. Wu, Z. S. et al. 3D Nitrogen-Doped Graphene Aerogel-Supported $\mathrm{Fe}_{3} \mathrm{O}_{4}$ Nanoparticles as Efficient Eletrocatalysts for the Oxygen Reduction Reaction. J. Am. Chem. Soc. 134, 9082-9085 (2012).

38. Maeda, H. \& Maeda, Y. An atomic force microscopy study of surface structures of colloidal beta-FeOOH particles forming smectic layers. Nano Lett. 2, 1073-1077 (2002).

39. Piao, Y. et al. Wrap-bake-peel process for nanostructural transformation from beta-FeOOH nanorods to biocompatible iron oxide nanocapsules. Nat. Mater. 7, 242-247 (2008).

40. Sathish, M., Tomai, K. \& Honma, I. Graphene anchored with $\mathrm{Fe}_{3} \mathrm{O}_{4}$ nanoparticles as anode for enhanced Li-ion storage. J. Power Sources, 217, 85-91 (2012).

41. Ferrari, A. C. et al. Raman Spectrum of Graphene and Graphene Layers. Phys. Rev. Lett. 97, 187401 (2006).

42. Zhang, X. et al. Nitrogen-doped graphene network supported copper nanoparticles encapsulated with graphene shells for surfaceenhanced Raman scattering. Nanoscale 7, 17079-17087 (2015). 
43. Zafar, Z. et al. Evolution of Raman spectra in nitrogen doped graphene. Carbon, 61, 57-62 (2013).

44. Zheng, J. G., Sterbinsky, G. E., Cheng, J. \& Wessels, B. W. Epitaxial $\mathrm{Fe}_{3} \mathrm{O}_{4}$ on $\mathrm{SrTiO}_{3}$ characterized by transmission electron microscopy. J. Vac. Sci. Technol. B 25, 1520-1523 (2007).

45. Barbieri, A., Weiss, W., MA Van Hove, M. V. \& Somorjai, G. Magnetite $\mathrm{Fe}_{3} \mathrm{O}_{4}(111)$ : surface structure by LEED crystallography and energetics. Surf. Sci. 302, 259-279 (1994).

46. Li, Z. et al. Combination of uniform $\mathrm{SnO}_{2}$ nanocrystals with nitrogen doped graphene for high-performance lithium-ion batteries anode. Chem. Eng. J. 283, 1435-1442 (2016).

47. XPS database on Web:http://www.lasurface.com/database/elementxps.php (December 2015).

48. Zhou, X. S., Wan, L. J. \& Guo, Y. G. Binding $\mathrm{SnO}_{2}$ Nanocrystals in Nitrogen-Doped Graphene Sheets as Anode Materials for Lithium-Ion Batteries. Adv. Mater. 25, 2152-2157 (2013).

49. Gutlich, P. et al. The valence states of nickel, tin, and sulfur in the ternary chalcogenide $\mathrm{Ni}_{3} \mathrm{Sn}_{2} \mathrm{~S}_{2}$-XPS, Ni-61 and Sn-119 Mossbauer investigations, and band structure calculations. Angew. Chem. Int. Edit. 38, 2381-2384 (1999).

50. Yang, Y. W. \& Fan, L. J. High-resolution XPS study of decanethiol on Au(111): Single sulfur-gold bonding interaction. Langmuir 18, $1157-1164$ (2002).

51. Fan, X. L. et al. Carbon encapsulated 3D hierarchical $\mathrm{Fe}_{3} \mathrm{O}_{4}$ spheres as advanced anode materials with long cycle lifetimes for lithium-ion batteries. J. Mater. Chem. A 2, 14641-14648 (2014).

52. Zhao, L. et al. $\mathrm{Fe}_{3} \mathrm{O}_{4}$ nanoplates/carbon network synthesized by in situ pyrolysis of an organic-inorganic layered hybrid as a highperformance lithium-ion battery anode. J. Mater. Chem. A 3, 14210-14216 (2015).

53. Guo, J. X., Zhu, H. F., Sun, Y. F. \& Zhang, X. Construction of sandwiched graphene paper@ $\mathrm{Fe}_{3} \mathrm{O}_{4}$ nanorod array@graphene for large and fast lithium storage with an extended lifespan. J. Mater. Chem. A 3, 19384-19392 (2015).

54. Saadat, S. et al. Coaxial $\mathrm{Fe}_{3} \mathrm{O}_{4} / \mathrm{CuO}$ hybrid nanowires as ultra fast charge/discharge lithium-ion battery anodes. J. Mater. Chem. A 1, 8672-8678 (2013).

55. Liang, J. F. et al. Deposition $\mathrm{SnO}_{2} /$ Nitrogen-Doped Graphene Nanocomposites on the Separator: A New Type of Flexible Electrode for Energy Storage Devices. ACS Appl. Mater. Inter. 5, 12148-12155 (2013).

56. Tung, V. C., Allen, M. J., Yang, Y. \& Kaner, R. B. High-throughput solution processing of large-scale graphene. Nat. Nanotechnol. 4, 25-29 (2008).

\section{Acknowledgements}

Part of the work was funded by the Natural Science Foundation Program of China (61574039), the Natural Science Foundation Program of Fujian Province (2015J01252), the Science Development Foundation of Fuzhou University (2012-XQ-40), and the Foundation Program of the Ministry of Education for Returned Exchange Personnel (LXKQ201101).

\section{Author Contributions}

Z.Y., T.G. and Z.G. conceived and designed the experiments. Z.Y., K.Q., J.L. and W.Y. performed the experiments and analyzed the data. J.L., J.A. and Y.Z. performed the XRD, Raman, TEM and XPS characterization. Z.Y., X.Z., S.X., T.G. and Z.G. wrote the manuscript and checked the manuscript in grammars. All the authors discussed and commented on the manuscript.

\section{Additional Information}

Supplementary information accompanies this paper at http://www.nature.com/srep

Competing financial interests: The authors declare no competing financial interests.

How to cite this article: Yang, Z. et al. Encapsulation of $\mathrm{Fe}_{3} \mathrm{O}_{4}$ Nanoparticles into N, S co-Doped Graphene Sheets with Greatly Enhanced Electrochemical Performance. Sci. Rep. 6, 27957; doi: 10.1038/srep27957 (2016).

(c) (i) This work is licensed under a Creative Commons Attribution 4.0 International License. The images or other third party material in this article are included in the article's Creative Commons license, unless indicated otherwise in the credit line; if the material is not included under the Creative Commons license, users will need to obtain permission from the license holder to reproduce the material. To view a copy of this license, visit http://creativecommons.org/licenses/by/4.0/ 